\title{
Perspectives
}

\section{Perspectives of Safe Work Practices: Improving Personal Electrical Safety of Low-Voltage Systems from Electrical Hazards}

\author{
Youssef Mobarak \\ Electrical Engineering Department, \\ Faculty of Engineering, King Abdulaziz University, \\ Rabigh, Saudi Arabia \\ ysoliman@kau.edu.sa
}

\author{
Abdullah Alshehri \\ Electrical Engineering Department, \\ Faculty of Engineering, King Abdulaziz University, \\ Rabigh, Saudi Arabia \\ aaashehri@gmail.com
}

\begin{abstract}
A person's understanding of a safety hazard has a dramatic effect on his or her behavior. An in-depth understanding of a hazard usually results in a healthy respect for what can happen. People who know the most about a specific hazard tend to rely more heavily on procedures and plans to guide their actions. Personal protective equipment selection and use are influenced by increased understanding of a hazard. Training and training programs are influenced by the depth of knowledge held by all members of the line organization. Recent work has focused attention on the thermal effects of arc flashes. However, when electrical energy is converted into thermal energy in an arcing fault, still another energy conversion is taking place. Applications are on record that suggest that a considerable amount of force is created during an arcing fault. Concrete block walls can be destroyed by the increased pressure that is created during an arcing fault. This study is present about preventing injuries to people. We will study about injuries and then develop some understanding about electrical hazards. Also, we will present about safe work practices, responsible, and then about what makes us act as we do.
\end{abstract}

Keywords-Personal Electrical Safety; Injuries; Electrical Hazards; Safe Work Practices; Responsibility.

\section{INTRODUCTION}

Electricity hazards have been well documented through the years and various papers, guides and books have been published that focus on such hazards, the reasons, analysis, prevention measures etc in various applications [1-65]. An extended list is provided in the references section. Historically, the obvious issue of direct contact was first reported but in the mid-80s the issue of arc flashes also started to gain attention. Since most arc-flash burns are recorded just as burns, some estimates suggest that 80 percent of all injuries from an electrical hazard is the result of an arc. The plasma in an electrical arc can reach $35,000{ }^{\circ} \mathrm{F}$. In fact, it will reach that temperature unless the energy source is removed before it gets there. People have been fatally burned at distances greater than 10 feet from the arc. In one arcing-fault incident, two people who were standing about 18 feet from an electrical arc were fatally burned. More than 2000 people are admitted to burn centers annually with severe electrical burns. Several standards and guides ghave been published that focus on arc flashes. ArcPro is a commercially available software that will project an incident-energy calculation. Many commercially available system analysis computer programs, such as EDSA, also contain software that calculates incident energy. Many of the calculation methods do not correlate with one another. They might provide a different result. Insufficient information is available to suggest that one method provides more accurate information than another. Where do these conditions exist?.

The arc-flash issue can be reduced to these facts. You can calculate incident energy by one of several methods]. An employer/owner should provide enough information about the electrical circuit that enables a worker to select protective equipment. National Electrical Codes usually require a label on equipment where potential for an arc-flash injury exists. However, you really don't know how much protective equipment will prevent an injury. A worker should wear clothing that provides significant flash protection as his or her normal work clothes. You should also be advised that the PPE selected by any method will not necessarily eliminate an injury. Incident energy is calculated at a prescribed distance. If the PPE is 100 percent effective at that distance, some part of the worker's body probably will be closer and subjected to greater thermal energy. The best alternative is to create an electrically safe work condition. If the source of energy is removed with assurance that it cannot reaccumulate, all exposure to an electrical hazard has been removed. This practice should always be the first option. Stop, stand still, think. Does something seem out of place? Smell. Equipment that is beginning to fail frequently gives off an unusual smell. Feel. Does the equipment or device feel warm or hot to the touch? 
Listen. Is there an unusual sound? The first generally recognized hazard associated with electrical energy was fire. These conditions frequently result in a fire. There is much left to discuss. Review your employer's plan and procedures. Minimize exposure to the hazard by doing as much work as possible before exposing the hazard. A barrier should be installed to cover any conductor that must remain energized. A rented generator be installed to permit the equipment to be completely locked out, and safety grounds help to eliminate the possibility of an unexpected backfeed.

\section{INJURIES}

For an injury to occur, an unintended release of energy or an unexpected contact with some source of energy must occur. Only an unintended interaction with some source of energy can cause an injury. The exposure may be intended or unintended, can only be the result of an unsafe condition, an unsafe act, or through the use of unsafe equipment. An unsafe act is when an energy release is the result of a person's action, such as if a person cuts the ground probe from a NEMA 5-15 cord cap. An unsafe condition is when the working environment is influenced by a condition that results in a release of energy, such as if a person leaves a hole in the floor unguarded or uncovered. Unsafe equipment might be poorly maintained equipment, or it might be an electrical circuit that has oversized fuses. If we lumped all unsafe conditions and all unsafe equipment together, they would account for about one-third of all injuries. Unsafe acts are the basic cause for two-thirds of all injuries. We could also categorize all injuries by the type of energy. If we did, electrical injuries would be the largest category.

\section{A. Causes of Injuries:}

This section compares unsafe equipment and unsafe conditions with unsafe acts. As the chart suggests in Figure 1a, unsafe acts is the major cause of injury. This chart also suggests that if we could somehow eliminate unsafe acts as a cause of injury, we could reduce the number of electrical injuries by a significant degree. Once an incident is in progress, a person can do little to avoid being injured. The trick then, is to take some action before an incident has a chance to begin.

\section{B. Heinrich's Relationship:}

A theory developed by H.W. Heinrich states that for every 300,000 unsafe acts, there are 30,000 near misses, 300 recordable injuries, 30 lost-time injuries, and 1 fatality as shown in Figure 1b. Over the years, these relationships have proven to be relatively accurate. Some people feel that if the energy source is electrical, then a zero can be taken from the relationship. However, that contact with an energized electrical conductor has a very significant chance of electrocution.

\section{Injury Analysis:}

This analysis of data suggests that an injury from electrical energy fits into these categories. The study used data that was collected over a ten-year period from 120,000 employees. The data shows that a population of this size can expect to have 125 lost time injuries each year. Of these injuries, $25.7 \%$ injuries involve the eyes, $21 \%$ result in permanent disability and $2.4 \%$ are fatal. For every 25,000 workers, a fatality is experienced each year. It should be noted that these statistics don't include burn injuries from either current flow or arc flash because they are categorized as burns
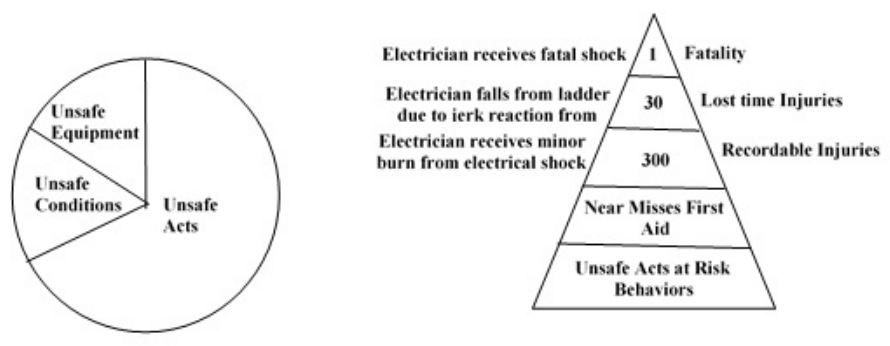

Fig. 1. Injuries, and Heinrich's Relationship

\section{ELECTRICAL HAZARDS}

\section{A. Electric Fire:}

A fire caused by high-resistance connections might occur when mechanical joints in an electrical conductor loosen as the conductor material heats and cools in its normal use cycle. The heating and cooling cycle causes the connector to expand and contract. The connector material stretches during this cycle, resulting in decreased contact pressure. Conductor material can flow away from the point where pressure is applied, which causes the pressure to decrease. The high-resistance connection generates heat that can, in-turn, ignite any nearby flammable material. An improper welding path can cause sparks at remote locations. If any flammable material is nearby, the sparks can result in ignition. If electrical insulating material is inadequately rated, the conductor can contact a surface at a different potential. Of course, hazardous flammable material can be ignited by either of the above means or by a static discharge. In either case, a fire will likely result.

\section{B. Electric Shock:}

No one really knows how many non-fatal shock accidents happen each year. However, records show that at least 30,000 do occur. Now consider that perhaps 1 in 50 maybe 1 in 100 shock accidents are recorded. An electrocution is an electrical shock that is of a magnitude large enough or long enough to result in a fatality. Records show that, in industry, over 600 people are electrocuted each year. Electrocution is the sixth leading cause of industrial fatalities. Figure 2 illustrates the number of electrocutions, by year, from 1992 to 1998. A short glossary follows:

Touch Potential: Electricity always takes the path of least resistance. If a person touches an energized point with a hand, and the other hand is in contact with ground or a grounded object (Figure 3a), the current will likely flow from the one hand to the other. This type of contact is called hand to hand.

Step Potential: A similar current path can exist from one foot to the other. This foot-to-foot contact is called step potential as in Figure 3b. A potential difference exists between 
a person's feet. That current will flow through the trunk of the body.

Touch Potential: Still another type of touch potential can exist (Figure 3c), as the path that current might take with a hand-to-foot contact. When contact is first made with an energized conductor, the surface contact between the skin and the conductor is high. As the current increases, the contact resistance is driven lower. If the skin's surface should break, contact resistance effectively disappears. Only internal impedance remains. Blood and nerve tissue are very good conductors. Body tissue is primarily a saline solution that conducts electricity very well. At first contact, the current probably will flow across the surface of the skin.

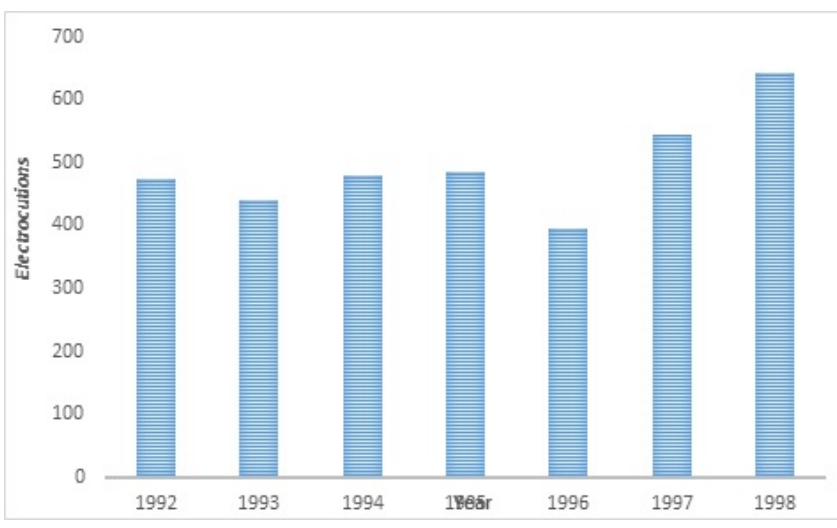

Fig. 2. Electrocutions by Year
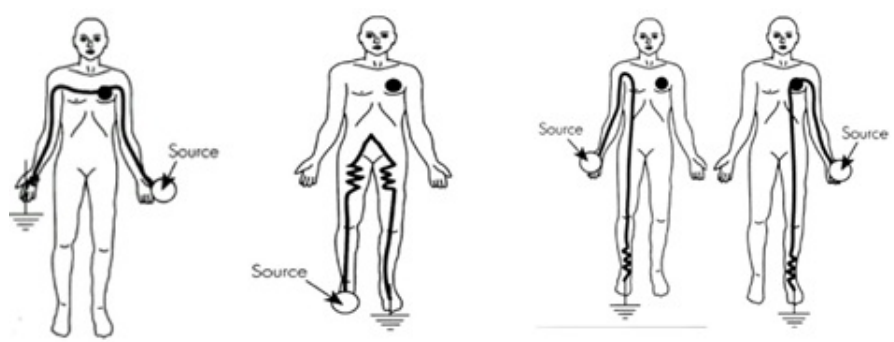

Fig. 3. Electrical shock types

Characteristics of the Body: The body can be considered to be essentially an electrical system. A small voltage is chemically generated within the brain, and the nerves deliver the signal to the muscle. The current flow is in the microampere range. The muscle reacts to the strength of the signal. A stronger signal means to constrict more. If an external source of voltage sends a signal to a muscle, the muscle reacts as if the signal were a normal signal. If the external signal is greater than the signal generated by the brain, the muscle is told to stay clamped. The let-go threshold has been reached. Automatic body functions such as heartbeat and breathing become confused at the powerful signal. They cease to operate normally. Fibrillation of the heart occurs quite rapidly. Figure 4 shows how much current can be expected to flow in case a person makes contact with ordinary utilization voltages. Best dry conditions on this chart, the green line indicates the amount of current that will flow under the best of conditions. The worker is wearing dry gloves. The worker's shoes are in good condition. The black vertical line at the left represents 110 volts. Reading across to the current line, we can see that the worker will experience a current flow of about $14 \mathrm{~mA}$. The vertical line on the right represents 480 volts. Again reading to the left axis, we can see that the worker will experience a current flow of about $55 \mathrm{~mA}$. The notes on the right side of the chart suggest what kind of reaction a person's body might experience. Worst but normal conditions are shown in Figure $4 \mathrm{~b}$, this graph represents a different set of conditions. The worker has been at it for a while, and his or her gloves are damp from perspiration.

The impedance introduced by the gloves is reduced. The green line still represents the dry conditions we saw in Figure 4a. The red line has been added to represent the amount of current flow that is likely in event of contact with an energized conductor with the damp gloved hand. Again, the vertical line on the left represents 110 volts. The vertical line on the right represents 480 volts. As you can see, the current flow at 110 volts is well into the let-go threshold. The current flow at 480 volts is well into the range that will cause fibrillation.

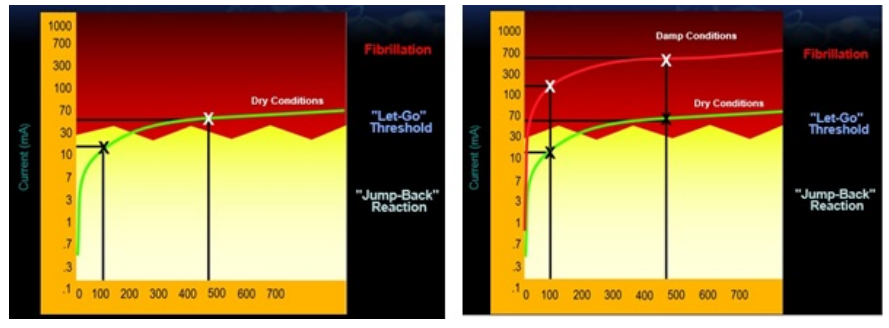

Fig. 4. Expected current flow in a person

Exposed to Shock: A person is likely to receive an electrical shock any time he or she contacts an exposed energized conductor. An inadequate ground of any type can cause a voltage to exist at points where it is unexpected. Poor equipment design or installation can result in conductive components that are exposed. For instance, if a hot and neutral conductor are interchanged, an external surface can be energized. Equipment must be maintained so that the installed condition is approximated for the life of the installation. The most common means of exposure to shock is by poor work practice or procedures. Injuries frequently occur when the worker believes that the conductor is de-energized. Should a condition exist that permits a large current to flow through earth, such as a significant fault or lightning discharge, a voltage gradient is generated in the earth path. If a person contacts two points along the path of current flow, some current is likely to be diverted through the person's body. Some informative pictures are shown in Figure 5.

Electric Shock Hazard and Protection: Table I shows what a body's reaction might be to various amounts of current. The differences in the two columns to the right are not really related to males and females. Instead, females are generally assumed to have a smaller body frame. The issue seems to be current density. 
Protect from Exposure to Shock: So, you avoid exposure to electrical shock or electrocution. Shut it off - lock it out. Stay outside the safe approach boundary. Wear protective equipment that is adequately rated for the potential exposure. Keep your grounding system in good repair. This means that you have to test them from time to time. Keep all doors closed and covers in place. If the door is closed, there is no exposed energized conductor. Treat energized electrical conductors with respect. The insulation could be damaged. The insulation could be deteriorated with no visual indication. Train people to be able to recognize when and how exposure to electrical shock can exist. Train people to understand how to completely avoid or minimize their exposure to shock by selecting and wearing adequate protective equipment. Train people to understand and accept their personal limitations. They should know the limit of their knowledge and their skill. Train people to practice continual awareness of their exposure to electrical shock. Use signs and labels to warn people that an electrical hazard exists and that their exposure is elevated.
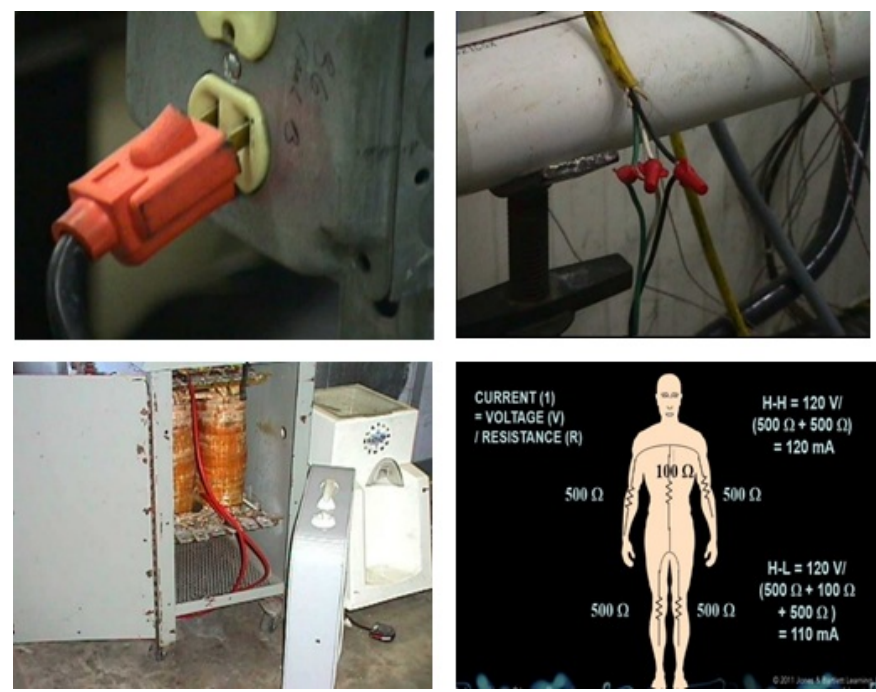

Fig. 5. Electric Shock Hazard and Protection

TABLE I. EFFECT OF CURRENT ON THE HUMAN BODY

\begin{tabular}{|l|c|c|}
\hline \multicolumn{1}{|c|}{ Effect } & $\begin{array}{c}\text { AC in mA } \\
\text { (Males) }\end{array}$ & $\begin{array}{c}\text { AC in mA } \\
\text { (Females) }\end{array}$ \\
\hline Slight sensation in hand & 0.4 & 0.3 \\
\hline Perception threshold & 1.1 & 0.7 \\
\hline Shock not painful Muscular control not lost & 1.8 & 1.2 \\
\hline Shock painful Muscular control not lost & 9.0 & 6.0 \\
\hline $\begin{array}{l}\text { Shock painful and severe Muscular control not } \\
\text { lost }\end{array}$ & 23.0 & 15.0 \\
\hline $\begin{array}{l}\text { Shock possible ventricular fibrillation effect } \\
\text { from 3-second shocks }\end{array}$ & 1100.0 & 100.0 \\
\hline
\end{tabular}

\section{Arc Flash:}

When an arc-flash event happens, pressure that is created by the superheated air and vaporizing metal expels droplets of molten metal and other parts and pieces with great force. Arcflash events usually happen very quickly. Although many people have seen the effects of an arcing fault, most have never seen the event itself. Figures 6-7 shows stills from a video taken by a camera that shoots 30,000 frames per second. In the picture are two electricians mannequins, not real people. One is near the equipment, and the other is near the right side of the photo. Figure 7 are intended to illustrate the kind of pressure force that the person would feel on his or her body. Arcing faults may not be in a starter unit or a circuit breaker enclosure a fault can occur at any place in the circuit.

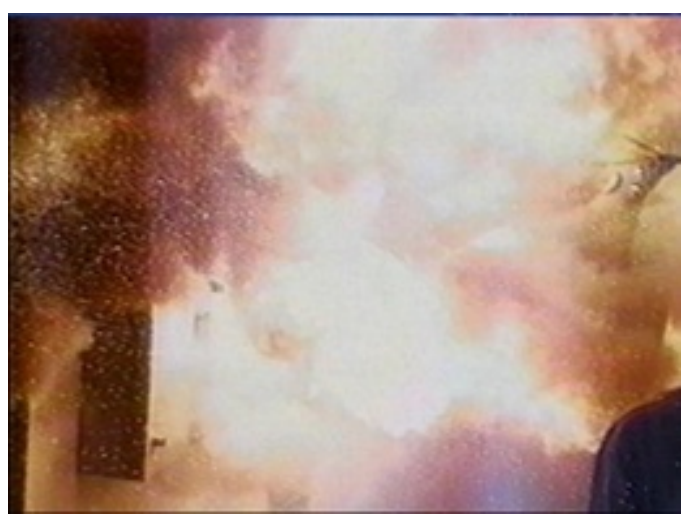

Fig. 6. A photograph of a grab
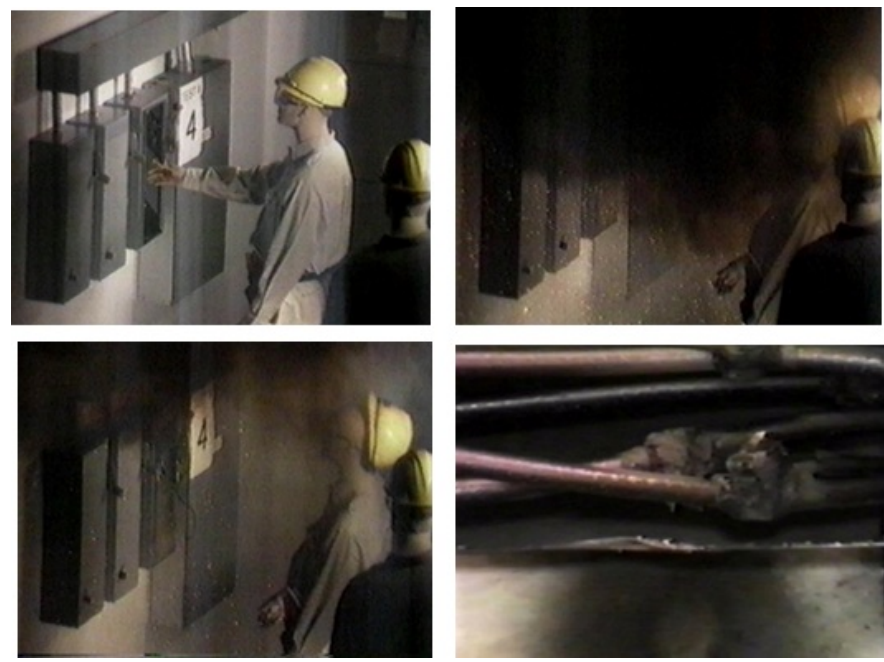

Fig. 7. The kind of pressure force that the person would feel on his or her body

Electrical Arc Burn Hazards: The plasma of an electrical arc can reach a temperature of $35,000^{\circ} \mathrm{F}$. The plasma temperature does not reach that temperature instantaneously. Normally, the overcurrent device removes the energy source within two or three seconds. However, the rate of temperature rise is considerable. Usually an overcurrent device operates within the first second and quenches the arc. Sometimes the overcurrent device does not operate as intended, and the arc temperature gets quite high. In a normal situation where the overcurrent device removes the energy in less than one second, the plasma temperature can reach 15,000 to $17,000{ }^{\circ} \mathrm{F}$. Ordinary street clothing can ignite if its temperature reaches 700 to $1400^{\circ} \mathrm{F}$. The ignition temperature varies as the construction material changes from nylon, polyester, or similar material to cotton and wool. If a person's clothing ignites, the 
burning material will subject the person to about $1400^{\circ} \mathrm{F}$. However, the person will be subjected to that high temperature for several seconds before the flame is extinguished or the clothing is removed. Some materials will melt when burning and deposit the molten material onto the surface of the person's skin. Copper melts at about $1800^{\circ} \mathrm{F}$. The metal droplets that are expelled during the faulted condition are also at that temperature. Sometimes the droplets will melt through the clothing, but sometimes the clothing will be ignited by the molten copper. Table II shows what might happen to a person's skin if subjected to elevated temperature.

TABLE II. SKIN TEMPERATURE TOLERANCE RELATIONSHIP

\begin{tabular}{|c|l|l|}
\hline $\begin{array}{c}\text { Skin } \\
\text { temperature }\end{array}$ & $\begin{array}{c}\text { Time of skin } \\
\text { temperature }\end{array}$ & \multicolumn{1}{|c|}{ Damage caused } \\
\hline $110^{\circ} \mathrm{F}$ & 6.0 Hours & Cell breakdown begins \\
\hline $158^{\circ} \mathrm{F}$ & 1.0 second & Total cell destruction \\
\hline $176^{\circ} \mathrm{F}$ & 0.1 second & Second degree burn \\
\hline $200^{\circ} \mathrm{F}$ & 0.1 second & Third degree burn \\
\hline
\end{tabular}

Important Event Factors: Arc-flash events happen very quickly. Many people who were present when an arc flash occurred did not even see the flash. The events are very unpredictable. An arc flash might occur in one set of conditions and in similar conditions a second time might not occur. These events are normally started by a person doing something. Even when equipment fails, the event is usually precipitated by a person doing something. These events are not related to the system of grounding. Regardless of solid ground, resistance ground, or if the system is ungrounded, the events and their results seem to be the same. These events are not related to voltage. Instead, they are related to energy: specifically, the amount of energy that is available within the system at the point of the fault. These events usually happen as a result of movement. A contactor operating, a switch handle moving, an errant movement by a worker, or similar events normally initiate arc-flash events.

Approach Boundaries: The arc-flash protection boundary is related to arc flash only, with no relationship to electrical shock or electrocution. The limited, restricted, and prohibited approach boundaries are intended to trigger additional protective measures to prevent shock or electrocution. It is important to understand that the prohibited approach boundary represents a distance beyond which contact with an exposed energized conductor is likely. A work task that requires or enables an approach closer than this dimension should be prohibited. Figure 8 illustrates the four approach boundaries. Again, the limited, restricted, and prohibited approach boundaries represent increased exposure to shock. These boundaries are fixed, based on the circuit voltage. The arcflash protection boundary is not fixed. The distance moves in and out from the exposed energized conductor, based on the amount of energy that is available in the system. They are based on the system voltage and do not change from one circuit to another. The limited approach boundary may change, depending on the relative position of the worker. If the relation position can change, then the distance is moveable. Moveable means that the conductor might move, such as in an overhead line construction, or if the worker is on a moveable platform such as an articulating basket. Fixed means that the worker is on a stable platform, such as a floor, and the conductor is held in place, such as a buss within a piece of equipment, shock approach boundaries show in Table III.

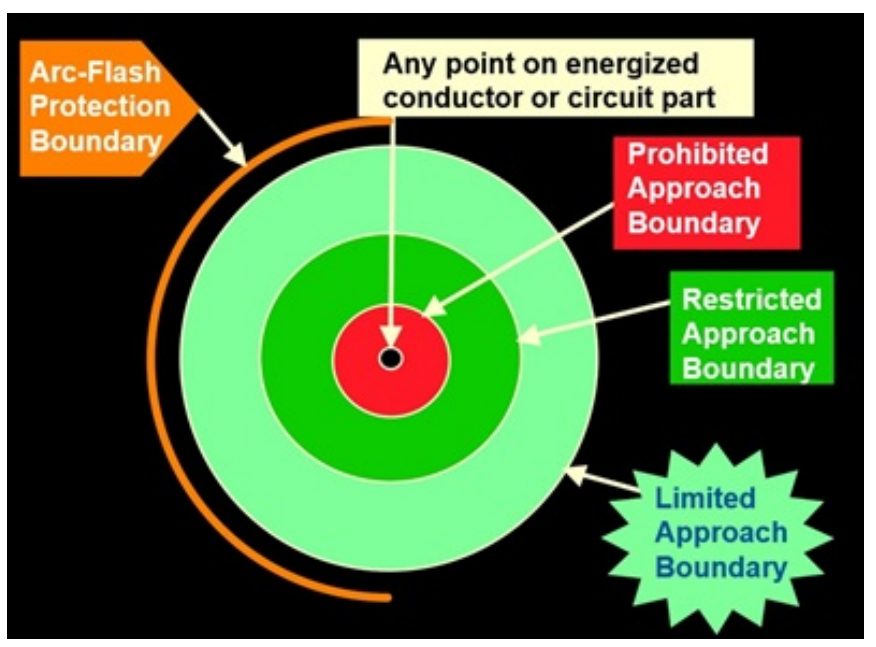

Fig. 8. Four approach boundaries

TABLE III. SHOCK APPROACH BOUNDARIES

\begin{tabular}{|c|c|c|c|c|}
\hline & \multicolumn{4}{|c|}{ Approach boundary } \\
\hline $\begin{array}{c}\text { Number } \\
\text { system voltage } \\
\text { range }\end{array}$ & \multicolumn{2}{|c|}{ Limited } & Restricted & Prohibited \\
\hline \multirow[t]{2}{*}{ Phase to phase } & $\begin{array}{l}\text { Exposed } \\
\text { movable } \\
\text { conductor }\end{array}$ & $\begin{array}{l}\text { Exposed } \\
\text { fixed } \\
\text { circuit part }\end{array}$ & $\begin{array}{c}\text { Includes } \\
\text { inadvertent } \\
\text { movement } \\
\text { adder }\end{array}$ & $\begin{array}{c}\text { Includes } \\
\text { reduced } \\
\text { inadvertent } \\
\text { movement } \\
\text { adder }\end{array}$ \\
\hline & \multicolumn{4}{|c|}{ Energized part employee - distance in feet - inches } \\
\hline 0 to 300 & $\begin{array}{c}\text { Not } \\
\text { specified }\end{array}$ & $\begin{array}{c}\text { Not } \\
\text { specified }\end{array}$ & $\begin{array}{c}\text { Not } \\
\text { specified }\end{array}$ & $\begin{array}{c}\text { Not } \\
\text { specified }\end{array}$ \\
\hline 51 to $300 \mathrm{~V}$ & $10 \mathrm{ft} .0$ in. & $3 \mathrm{ft} .6$ in. & $\begin{array}{c}\text { Avoid } \\
\text { contact }\end{array}$ & $\begin{array}{c}\text { Avoid } \\
\text { contact }\end{array}$ \\
\hline $\begin{array}{c}\text { Over } 300 \mathrm{~V} \\
\text { not over } 750 \\
\mathrm{~V}\end{array}$ & $10 \mathrm{ft} .0$ in. & $3 \mathrm{ft} .6$ in. & $1 \mathrm{ft} .0$ in. & $0 \mathrm{ft} .1$ in. \\
\hline $\begin{array}{c}\text { Over } 750 \mathrm{~V} \\
\text { not over } 2 \mathrm{kV}\end{array}$ & $10 \mathrm{ft} .0$ in. & $4 \mathrm{ft} .0$ in. & $2 \mathrm{ft} .0$ in. & $0 \mathrm{ft} .3$ in. \\
\hline $\begin{array}{c}\text { Over } 2 \mathrm{kV} \text { not } \\
\text { over } 15 \mathrm{kV}\end{array}$ & $10 \mathrm{ft} .0$ in. & $5 \mathrm{ft} .0$ in. & $2 \mathrm{ft} .2$ in. & $0 \mathrm{ft} .7$ in. \\
\hline $\begin{array}{c}\text { Over } 15 \mathrm{kV} \\
\text { not over } 36 \\
\mathrm{kV}\end{array}$ & $10 \mathrm{ft} .0$ in. & $6 \mathrm{ft} .0$ in. & $2 \mathrm{ft} .7$ in. & 0 ft. 10 in. \\
\hline
\end{tabular}

Protective Clothing and Personal Protective Equipment (PPE): A flash-hazard analysis is intended to determine the amount of available fault energy that the system can provide. Available energy is dependent on the size of the transformer together with the impedance of the circuit. Technical papers have defined incident energy as the amount of energy that might be "incident" on a material that is at a specified distance from the arc. If the incident energy is known and protective clothing is selected that has a rating equal to or greater than the 
available energy, then an injury is unlikely. Protective clothing can be selected based on the amount of incident energy.

Flash Protection: Up to 6 inches: Where the transformer ahead of the equipment is $500 \mathrm{kVA}$ or smaller and the overcurrent protection is current limiting. Up to 18 inches: Where the transformer ahead of the equipment is $75 \mathrm{kVA}$ or smaller and without current limiting overcurrent protection. More than 18 inches: Where the transformer is larger than 500 $\mathrm{kVA}$ and without current-limiting overcurrent protection. As the size of the transformer increases above $500 \mathrm{kVA}$, the amount of needed protection also increases. Where the transformer is more than $750 \mathrm{kVA}$, incident energy should be calculated or determined $\mathrm{H}$ in the Electrical Safety Program Guide.

Use Protective Clothing: Always wear flame-resistant clothing. The greater protective value of the clothing, the greater the protection. Cover every body part that is within the flash-protection boundary with protection. Keep all fasteners closed. Buttons and zippers should be buttoned or zipped. Wear heavy-duty leather gloves. Leather is not classified with an established rating. However, normally an arc-flash event is so fast that the leather will provide the necessary protection. Sometimes the cotton stitching that holds the gloves together will burn, but the gloves will hold together long enough to afford significant protection. Wear heavy-duty leather shoes. Like heavy-duty leather gloves, leather shoes will afford significant protection. Workers should not wear sneakers or shoes of similarly light construction. Wear polycarbonate safety glasses in addition to any other face protection. The polycarbonate material protects the eyes from the ultraviolet energy.

\section{Arc Blast:}

The kind of injuries that are typical with an arc blast are broken bones when a body is literally thrown across a room. Metal parts and pieces are propelled across a room. There is a tremendous increase in pressure during an arcing fault. When the temperature of the plasma exceeds the melting point of copper, the conductor changes state from solid to liquid. As the temperature exceeds the boiling point of the liquid copper, the copper liquid becomes copper vapor. Now, when water changes state from liquid to steam, the water volume expands four times, unless constrained in an enclosure. When the copper vaporizes, it expands many thousands of times. Even without a containing enclosure, the speed at which the change of state occurs is so fast that there is a very significant increase in pressure surrounding the plasma. A pressure wave is created by the leading edge of this pressure buildup. Without an enclosure, the pressure wave travels outward from the arc until the volume is large enough for the atmospheric pressure to stabilize. The air surrounding the arc plasma is also heated very rapidly, increasing the pressure buildup. These results are similar to a lightning bolt. The conducting plasma is very hot, and thunder is the acoustic response to the pressure wave.

Pressure measured means that a force will be applied for each unit of surface area. If we make some assumptions about the surface area of an average electrician, then we can estimate the amount of force that an electrician would feel from the leading edge of the pressure wave. Figure 9 is intended to help make that judgment. One axis is marked in distance from an electrical arc, and the other axis represents the amount of force that an electrician would feel for a specific arcing fault. The diagonal lines represent an electrical fault current.

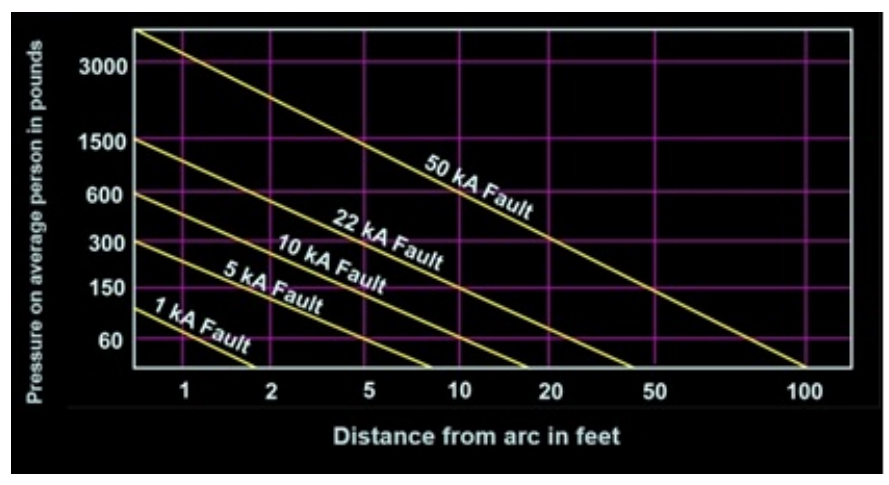

Fig. 9. Arc-blast pressure on human body

Arc-Blast Injuries: When the wave front hits the worker from the front, the pressure at his or her back is still at atmospheric pressure. A differential pressure will exist from the front to the back of the worker. A differential pressure will also exist from the external surface of the worker and all internal surfaces inside the worker. Injuries that might result from these differences in pressure include broken bones, cuts, and contusions. Sensitive components of the inner ear can easily be damaged. Internal organs can receive significant damage. The rapid increase in pressure can destroy the electrical equipment and expel parts and pieces with tremendous force.

Avoid Arc-Blast Injury: If an arcing fault is impossible, then the chance of an arc-blast injury does not exist. Any person who happens to be nearby when an arcing fault occurs is exposed to an injury from arc blast. Experience shows that if the equipment is not arc-resistant equipment, the chance of the enclosure being destroyed is significant. Maintain equipment and systems adequately. The integrity of electrical enclosures is very important. Coordinate the overcurrent devices so that minimum time is required to clear the fault. Flame-retardant PPE is not intended for protection from arc blast. However, arc-flash PPE might be a blend that includes abrasion-resistant textile. It is not possible for there to be exposure to injury from arc blast without a simultaneous exposure to arc flash.

\section{E. Safe Work Practices:}

The plan should identify each step in the job and consider electrical hazards at each step. The plan should identify all hazards to which a worker might be exposed. The plan should consider the type and degree of exposure to each hazard. The grounding system is a primary strategy of the NEC and serves to limit potential differences between conductive components and structures. Inadequate maintenance will permit dangerous potentials to exist. Procedures and policies contain wisdom that has been derived in the past. Workers should always implement each requirement of the procedure. 
Electrically Safe Work Condition: Identify all sources of energy from drawings. The drawings must be up to date. If the information on the drawing is inadequate, the worker is at an elevated risk of injury. It is important to ensure that disconnecting devices are rated for operation under load. As equipment ages, the failure rate increases. Sometimes the mechanical linkage in a disconnecting means fails, and all phases fail to open. Where it is physically possible, open the door and look at each phase contact to make sure that an opening exist in each phase conductor. Install lockout devices together with tags on all lockout points identified in the first step. Always test for voltage with an adequately rated voltmeter. We recommend that a single-function device be the instrument of choice to avoid the possibility of setting the meter on the wrong scale. The device should be listed by an independent testing laboratory. If there is any possibility that the equipment could become reenergized by an overhead line that falls or by induction coupling from another source or by any component failure, then a ground set should be installed.

Plan the Work: A work plan is a sequential listing of all the steps necessary to accomplish a job assignment. Begin the process by identifying each step and writing the plan on paper. If the work sequence is simple and each step easily remembered, it may not be necessary to write the plan on paper. However, a written plan is always an advantage. Identify and gather necessary procedures, manufacturer's information, or drawings. Review the work plan with someone else who is qualified to execute the job. Identify all hazards associated with the work. Be sure to consider both electrical and nonelectrical hazards. Create an electrically safe work condition. If any PPE is needed, gather it all together, then inspect it to make certain that it will function as needed. Assemble all test equipment that will be needed to perform the task and inspect it to ensure that it is not cracked, broken, or otherwise damaged. Seek authority to perform the work. No exposure to an electrical hazard should be accepted without questioning the necessity to do so. Ensure that the line organization is willing to accept any increased exposure.

Plan Every Job: A plan is a step-by-step list of all steps necessary to complete a job. The job might be either small or large. However, no job should be started until a plan is made. Every person who will participate in or be associated with the job must have the same plan. If someone does not understand the plan, it is likely that something will go wrong. To plan the job, break it down into small steps. The steps identify the sequential process that must be accomplished to execute the job. All tasks should be planned. The plan should clearly identify the scope of the job. Any change in scope should be cause to stop the work process and generate a new plan with the new scope or modify the original plan. Everyone must be advised of the change in the plan. The plan should identify the boundaries of the job. Everyone must understand boundaries and then respect those boundaries. Work that is not within the recognized boundary must not be performed. The plan should clearly point out the time frame in which the job is expected to be completed. It may not be necessary for the plan to be written. The key is whether everyone involved in the job understands the plan. It is important that the plan be reviewed by someone who was not involved in producing the plan. If the plan is in writing, the review is more reliable. When reviewing the work plan, think about what could go wrong. The job lineup should include information about emergency procedures. What device will be used in case of an emergency, where is the communication device, where is the fire extinguisher, and what is to be done if there is a technical problem. Make sure that all tools that are needed to perform the task are available. When exposure to an electrical hazard already exists, it is not the right time to be looking for a tool. Workers are inclined to improvise a tool and use it improperly if a tool is needed and not readily available. If a special tool is needed, then be sure to procure the tool and have it available.

Isolate the Equipment: The term CLT-3 means clear, lock, tag, try, and test.

- Clear - People should be cleared away from the equipment and the electrical circuit that will be involved in the work task.

- Lock - Locks should be installed in accordance with an established procedure or plan. Installation of lockout devices should be one of the steps that is executed when establishing an electrically safe work condition

- Tag - Together with locks, tags and their attachment devices make up a lockout device that should be installed when establishing an electrically safe work condition.

- Try - Equipment that has a push button and is capable of running should be tried. Trying to run the equipment is one indication that the correct disconnecting means has been opened.

- Test - For our purposes, testing for the absence of voltage is a critical step to ensure that no voltage exists on the exposed conductor.

Where it is physically possible, visibly verify that a break in all the power conductors exists. Always test every conductor before touching it. Test every conductor every time. If it is necessary to leave the work site, even for a few minutes, test every conductor when you return to the work location.

Assess People's Abilities: Consider the qualifications of the person(s) that will perform the work task. When a work task is begun, the worker's occupation, title, or job classification has little bearing on whether they can avoid an incident or not. Knowledge and skill are the only characteristics that will help prevent an incident. Think about the person's experience and his or her state of training. The person had sufficient training to execute the physical aspects of the work task. The person had sufficient training to recognize and avoid electrical hazards. The person have the knowledge about protective strategies to avoid initiating an incident. The worker have physical dexterity to perform the task. The worker in a mental condition that enables him or her to remain focused on the work task. Think about whether you have the skill to evaluate the condition of the worker. You understand the hazards enough to evaluate the exposure and determine if the risk is acceptable. It necessary to review the work with 
someone who is better qualified to determine if the risk is both necessary and acceptable.

The employer, the employee, and the owner are all responsible. They are each responsible for some element of the process of keeping people from being injured. For the process to be effective, each of these parts must be involved. The employer is responsible for:

- Establishing an electrical safety programme for the overall organization

- Defining and publishing safety policies and procedures

- Providing safety equipment that is needed to minimize exposure to electrical hazards

- Providing safety training for employees that enables each worker to know what hazards

The employee is responsible for implementing the procedures that are defined by the employer. However, it is not that simple. Each employee should provide the feedback that is necessary to keep procedures and practices up to date. Employees are responsible for ensuring that training provided by the employer is understood. Employees must be an integral part of the process for preventing injury to themselves and their fellow workers. The owner is inherently responsible for contactors that are working on site. In the strictest sense, the contractor might be the employer. However, the owner must make sure that the contractor is advised of all safety hazards to which contract employees might be exposed. The owner might be the landlord for a multinational corporation, or it might be the person who operates the facility for a small company. The owner must make certain that the contractor has been informed about hazards that exist on the site and should make certain that the contractor has an electrical safety programm that addresses the hazards which exist on the site.

\section{CONCLUSIONS:}

This study focuses on safe work practices especially in terms of electrical hazards and actually arc flash hazards. Potential hazards, causes, impacts and protection measures are discussed. A point by point guide is given for the person in charge. The basic steps are: think through the work plan and consider all possible exposure to the hazards of shock, arc flash, or arc blast. Determine what approach boundaries will apply to each step in the work plan. Consider every electrical conductor and every electrical component to be energized until the absence of voltage is verified. Ensure that all employees are properly trained and equipped and that safety procedures are updated and known to all.

\section{ACKNOWLEDGMENT}

This project was funded by the Deanship of Scientific Research (DSR), King Abdulaziz University, Jeddah, under Grant No. (829-19-D1437). The authors, therefore, acknowledge with thanks DSR's technical and financial support.

\section{REFERENCES}

[1] H. W. Heinrich, Industrial accident prevention: A scientific approach. New York, NY: McGraw-Hill, 1950

[2] H. W. Heinrich, Petersen, D., \& Roos, N. Industrial accident prevention. New York, NY: McGraw-Hill, 1959

[3] H. W. Heinrich, Petersen, D., \& Roos, N. Industrial accident prevention. McGraw-Hill, 1980

[4] A. Cakir, D. Hart, T. Stewart, Visual display terminals: a manual covering ergonomics, workplace design, health and safety, task and organization. Chichester: Wiley, 1980

[5] Ferry, T. S. Modern accident investigation and analysis: An executive guide. New York, NY: John Wiley \& Sons, 1981

[6] R. Campbell, R. Langford, Fundamentals of hazardous materials incidents. Chelsea, MI: Lewis Publishers, 1991

[7] M. Sanders, E. McCormick, Human factors in engineering And designs, 7th ed. Singapore: McGraw-Hill International Editions, 1993

[8] L. Harms-Ringdahl, Safety analysis: principles and practice in occupational safety, London, New York: Elsevier Applied Science, 1993

[9] J. Ridley, Safety at work, 4th ed. Butterworth Heinemann, 1994

[10] T. Kletz, Learning From accidents. Butterworth- Heinemann Ltd., 1994

[11] J. Harrington, G. Howard, Occupational health, 4th ed. Blackwell Science, 1998

[12] National Institute for Occupational Safety and Health, Worker deaths by electrocution: A summary of surveillance and investigative case reports. Cincinnati, 1998

[13] D. Cooper,Improving safety culture: A practical guide. England: John Wiley \& Sons, 1998

[14] R. Latino, K. Latino, Root Cause Analysis: improving performance for bottom line results. CRC Press, 1999.

[15] Handbook of laboratory safety, 5th ed. Boca Raton, FL: CRC Press, 2000.

[16] J. Stranks, The Handbook of health and safety practice, 5th ed. Pearson Education Ltd., 2000

[17] J. Ellis, Introduction to fall protection, 3rd ed. Des Plaines, IL: American Society of Safety Engineers, 2001

[18] Alaimo, R. J. Handbook of chemical health and safety. Washington, DC: American Chemical Society, Oxford University Press, 2001

[19] IEC. Degrees of protection provided by enclosures for electrical equipment against external mechanical impacts. IK code, 2002

[20] F. Manuele, Heinrich revisited: Truisms or myths. Itasca, IL: National Safety Council, 2002

[21] F. Manuele, On the practice of safety. New York, NY: John Wiley \& Sons. 2003

[22] J. Lam, Enterprise risk management: From incentives to controls. Hoboken, NJ: John Wiley \& Sons, 2003

[23] D. Goetsch, Occupational safety and health for technologists, engineers, and managers. Columbus, OH: Prentice Hall, 2004

[24] F. Hwang, The statistical methodology for social science: Structural equation model. Taipei: Wunan, 2004

[25] C. Shu, M. Lin, Planning, managing and designing in laboratories safety and health. Taipei: Gau-Lih Book Co., 2004

[26] IEC, Low-voltage electrical installations, part 4-41: Protection for safety-Protection against electric shock, 5th ed. 2005

[27] T. Krause, Leading with safety. Hoboken, NJ: John Wiley \& Sons, 2005

[28] R. Chapman, Simple tools and techniques for enterprise risk management. Chichester: John Wiley \& Sons, 2006

[29] National electrical safety code (ANSI/IEEE C2). New York, NY: Institute of Electrical and Electronics Engineers, 2007

[30] National electrical code (ANSI/NFPA 70). Quincy, MA: National Fire Protection Association, 2008

[31] NFPA 70E, Standard for electrical safety in the workplace. Quincy, MA: National Fire Protection Association, 2009 
[32] R. Lee, "The other electrical hazard: Electric arc blast burns", IEEE Transactions, Vol. IA-18, No. 3, 1982

[33] J. Zannetti, "Air pollution", First international conference on air pollution. Southampton: Computational Mechanics Publication, pp. 373 $-380,1993$

[34] Occupational Safety \& Health Council, Occupational Deaf, Green Cross, Occupation Safety \& Health Council, pp. 35-36, 1993

[35] R. Ted, G. Maury, "Estimating the costs of occupational injury in the United States", Accident Analysis and Prevention, Vol. 27, No. 6, pp. 741-747, 1995

[36] N. Akure, "A generalized cost-estimated model for job shops", International Journal of Production Economics, Vol. 53, pp. 257 263, 1997

[37] E. Rune, "How much do road accident cost the national economy", Accident Analysis and Prevention, Vol. 32, pp. 849-851, 1999

[38] Hong Kong Occupational Safety and Health Association, Causes of Accident and Investigation, Safety Bulletin, 9, pp. 10-12, 2001

[39] J. De Pasquale, E. Geller, "Critical success factors for behavior-based safety: a study of twenty industry-wide applications", Journal of Safety Research, Vol. 30, No. 4, pp. 237-249, 1999

[40] J. Williams, E. Geller, "Behavior-based intervention for occupational safety: critical impact of social comparison feedback". Journal of Safety Research, Vol. 31, No. 3, pp. 135-142, 2000

[41] S. Parker, C. Axtell, N. Turner, "Designing a safer workplace: Importance of job autonomy, communication quality, and supportive supervisors" Journal of Occupational Health Psychology, Vol. 6, No. 3, pp. 211-228, 2001

[42] J. Williams, "Improving safety leadership: Using industrial/organizational psychology to enhance safety performance", Professional Safety, Vol. 47, No. 4, pp. 43-47, 2002

[43] J. Barling, C. Loughlin, E. Kelloway, "Development and test of a model linking safety-specific transformational leadership and occupational safety", Journal of Applied Psychology, Vol. 87, No. 3, pp. 488-496, 2002

[44] E. Blair, "Culture \& leadership: Seven key points for improved safety performance", Professional Safety, Vol. 48, No. 6, pp. 18-22, 2003

[45] R. Carrillo, "Safety leadership formula: Trust + credibility + competence = results", Professional Safety, Vol. 47, No. 3, pp. 41-47, 2003

[46] D. Hofmann, F. Morgeson, S. Gerras, "Climate as a moderator of the relationship between leader-member exchange and content specific citizenship: Safety climate as an exemplar" Journal of Applied Psychology, Vol. 88, No. 1, pp. 170-178, 2003.

[47] C. Kuo, C. Tsaur, "Locus of control, supervisory support and unsafe behavior: The case of construction industry in Taiwan", Chinese Journal of Psychology, Vol. 46, No. 4, pp. 293-305, 2004

[48] E. Blair, D. Seo, M. Torabi, M. Kaldahl, "Safety beliefs and safe behavior among midwestern college students", Journal of Safety Research, 35, pp. 131-140, 2004

[49] M. Cooper, R. Philips, "Exploratory analysis of the safety climate and safety behavior relationship", Journal of Safety Research, Vol. 35, pp. 497-512, 2004

[50] D. Petersen, "Leadership \& safety excellence: A positive culture drives performance", Professional Safety, Vol. 49, No. 10, pp. 28-32, 2004

[51] D. Seo, M. Torabi, E. Blair, N. Ellis, "A cross-validation of safety climate scale using confirmatory factor analytic approach", Journal of Safety Research, 35, pp. 427-445, 2004

[52] L. Feisel, A. Rosa, "The role of the laboratory in undergraduate engineering education", Journal of Engineering Education, Vol. 94, No. 1, pp. 121-130, 2005

[53] R. Flin, S. Yule, "Leadership for safety: Industrial experience", Quality and Safety in Health Care, 13, pp.45-51, 2005

[54] T. Wu, "The validity and reliability of safety leadership scale in universities of Taiwan", International Journal of Technology and Engineering Education, Vol. 2, No. 1, pp. 27-42, 2005
[55] M. Mitolo, M. Tartaglia, G. Gruosso, A. Canova, "Evaluation of voltage exposures due to AC/DC stray currents", IEEE-IAS Industry Application Society 42nd Annual Meeting, New Orleans, LA, 2007

[56] T. Wu, C. Liu, M. Lu, "Safety climate in university and college laboratories: impact of organizational and individual factors", Journal of Safety Research, Vol. 38, pp. 91-102, 2007

[57] M. Modica, "Safety science: Applying safety in modern research laboratory", Professional Safety, Vol. 52, No. 7, pp. 24-30, 2007

[58] T. Wu, C. Li, Y. Shu, "Measuring safety culture in departments of electrical and electronic engineering at universities", 10th UICEE Annual Conference on Engineering Education, pp. 229-232, 2007

[59] K. Coghlan, "Investigating laboratory accidents", Professional Safety, Vol. 53, No. 1, pp. 56-57, 2008

[60] M. Tartaglia, M. Mitolo, "Evaluation of the prospective Joule integral to assess the limit short circuit capability of cables and busways", IEEE Industry Application Society (IAS) 43rd Annual Meeting, Edmonton, October 5-9 2008

[61] M. Mitolo, "Protective bonding Conductors: An IEC point of view", IEEE Transactions on Industry Applications, Vol. 44, No. 5, 2008

[62] A. Alvero, K. Rost, J. Austin, "The safety observer effect: the effects of conducting safety observations", Journal of Safety Research, Vol. 39, pp. 365-373, 2008

[63] A. Shariff, T. Keng, "On-line at-risk behaviour analysis and improvement system", Journal of Loss Prevention in the Process Industries, 21, pp. 326-335, 2008

[64] F. Manuele, "Serious injuries and fatalities: A call for a new focus on their prevention", Professional Safety, Vol. 53, No. 12, pp. 32-39, 2008

[65] N. Langerman, "Laboratory safety?", Journal of Chemical Health and Safety, Vol. 6, No. 3, pp. 49-50, 2009

[66] S. Mohamed, T. Ali, W. Tam, "National culture and safe work behavior of construction workers in Pakistan", Safety Science, Vol. 47, pp. 29-35, 2009

[67] A. Sharif, N. Norazahar, "At-risk behaviour analysis and improvement study in chemical engineering laboratories", International Journal of Chemical and Environmental Engineering, Vol. 2, No. 1, pp. 51-55, 2011 